\title{
A MODIFIED MATERIAL MODEL FOR THE FINITE ELEMENT SIMULATION OF MACHINING TITANIUM ALLOY Ti-6Al-4 V
}

\section{Y. Karpat}

To cite this article: Y. Karpat (2010) A MODIFIED MATERIAL MODEL FOR THE FINITE ELEMENT SIMULATION OF MACHINING TITANIUM ALLOY Ti-6AI-4 V , Machining Science and Technology, 14:3, 390-410, DOI: 10.1080/10910344.2010.512499

To link to this article: https://doi.org/10.1080/10910344.2010.512499

曲 Published online: 03 Nov 2010.

Submit your article to this journal $\asymp$

Џll Article views: 247

Citing articles: 9 View citing articles ๘ 


\title{
A MODIFIED MATERIAL MODEL FOR THE FINITE ELEMENT SIMULATION OF MACHINING TITANIUM ALLOY Ti-6AI-4V
}

\author{
Y. Karpat \\ Department of Industrial Engineering, Bilkent University, \\ Ankara, Turkey
}

Because of their desirable properties, such as high strength to weight ratio and corrosion resistance, titanium alloys are commonly employed in the aerospace and medical device industries. Titanium alloys are known to be difficult to machine, so the selection of cutting conditions with minimal experimental effort is important for manufacturers. Finite element modeling, which is an indispensable tool to understand the mechanics of machining, can also be utilized as an alternative method of process design as long as the finite element simulation input parameters are well defined. Developing a modified material model for titanium alloy Ti-6Al-4V by considering the relationships between strain, strain rate and temperature is the subject of this study. The flow softening behavior of the material at high strains is also examined. The influences of the material model parameters on the finite element simulation outputs are investigated. The finite element simulation results are found to be in agreement with the data available in the literature.

Keywords FEM, material model, machining, titanium

\section{INTRODUCTION}

Titanium alloy $T i-6 \mathrm{Al}-4 \mathrm{~V}$ exhibits a balanced set of desirable properties, such as high strength, good heat treatment capability, and resistance to corrosion and therefore it is the most commonly used titanium alloy in industry. Its low thermal conductivity, high chemical reactivity with cutting tool materials at elevated temperatures, and low modulus of elasticity make titanium alloy $T i-6 \mathrm{Al}-4 \mathrm{~V}$ difficult to machine. The heat generated during machining is concentrated at the cutting tool rake face and results in rapid wear of the cutting tools. Therefore, selecting cutting conditions, tool material and grade, and cutting tool geometry is important in order to obtain an acceptable level of productivity while machining titanium alloys. In addition, surface integrity of the

Address correspondence to Y. Karpat, Department of Industrial Engineering, Bilkent University, Ankara 06800, Turkey. E-mail: ykarpat@bilkent.edu.tr 
finished part has to be taken into account during the selection of cutting conditions. The main goal is to eliminate time consuming and costly experimental modeling approaches in favor of simulation models that can produce realistic results under practical cutting conditions.

Finite element models have been developed to study the mechanics of machining, optimization of cutting conditions, cutting tool design, and other aspects of machining. They are commonly employed to simulate titanium machining because of their capability to model serrated chip formation (Obikawa and Usui, 1996; Shivpuri et al., 2001; Calamaz et al., 2008; Umbrello, 2008). In general, adiabatic shearing is considered to be responsible for serrated chip formation. Materials that have both low thermal conductivity and yield stresses which exhibit high sensitivity to temperature are more susceptible to adiabatic shear. Recht (1964) developed a classical model for shear instability where the temperature gradient in the workpiece and the strain hardening behavior of the material are considered as factors to initiate shear instability in the workpiece.

Increasing temperatures in the primary shear zone due to shear deformation weaken the material by thermal softening. The low thermal conductivity limits the heat energy to diffuse in the workpiece; therefore, the deformation is concentrated in shear bands, leading to serrated chip formation (Komanduri and Turkovich, 1981; Burns and Davies, 2002). The material failure under adiabatic shear localization is related to large plastic deformation and microscopic damage (Komanduri and Brown, 1981). Timothy and Hutchings (1984) showed that the void formation in adiabatic shear bands in titanium alloys is closely associated with the thermal softening and local melting of the metal in the shear bands, which cause the sharp drop in the shear stress-strain response. Supporting findings were also reported in Giovanola (1988), where the propagation of adiabatic shear bands is considered as a major ductile failure mechanism which results in material separation along shear band. Owen and Vaz (1999) adopted this process and used a fracture criterion together with a failure softening model to describe void growth mechanism in machining titanium alloy $T i-6 A l-4 V$. Barry et al. (2001) reported experimental evidence of cracks on the chips collected during machining of titanium alloy $T i-6 A l-4 \mathrm{~V}$.

Studies on thermoplastic instability relate the formation and propagation of adiabatic shear bands to the dynamic recrystallization (DRX) phenomenon, which is the process of microstructure reformation and evolution resulting in newly crystallized small grains with very low dislocation density ( $\mathrm{Xu}$ et al., 2008). DRX has been documented for materials such as titanium, steels, copper, tantalum, etc. Rittel et al. (2008) have shown that DRX triggers adiabatic shear failure by observing 
dynamically recrystallized nanograins in titanium alloy $T i-6 A l-4 V$ subjected to impact loading to only half of its failure strain.

A critical strain, strain rate and temperature (usually considered to be $40-50 \%$ of the melting temperature of the material) are required for DRX to occur. Medyanik et al. (2007) studied the interaction between strain rate-temperature and showed that the critical temperature for DRX to occur decreases with increasing strain rate but reaches a steady state at a limiting value. The influence of dynamic recrystallization or other mechanisms leading to flow softening has been included in the material models during finite element simulation of machining processes. Rhim and Oh (2006) integrated the effect of DRX initiating after a critical strain value at temperatures higher than the half of the melting temperature in the material model for AISI 1045 steel. They used Johnson-Cook material model together with Avrami type of softening model.

Aurich and Bil (2006) used the same material model in 3D finite element model of machining and were able to obtain serrated chip formation with and without a damage model. Shivpuri et al. (2001) and Bäker et al. (2002) used "strain softening" in their finite element simulations without providing any mathematical formulation. Shivpuri et al. (2001) explained the softening of the flow stress at high strains as microstructural changes during machining. Recently, Calamaz et al. (2008) modified the J-C material constitutive model by multiplying it with a function in order to include strain softening in their simulations. Their explanation of the flow softening was given as platelet kinking/plastic buckling mechanism based on the experimental observations of Miller et al. (1999). Calamaz et al. (2008) considered the effect of strain softening to be greater at lower temperatures, and as temperatures increase, both strain hardening and strain softening effects are reduced. They were able to simulate serrated chip formation resembling experimental chips.

In finite element models, a constitutive material model is required to relate the flow stress to strain, strain rate and temperature. The experimental flow stress data are usually obtained by using SplitHopkinson bar tests performed under various strain rates and temperatures and the experimental data are used to calculate the unknown parameters of material constitutive models. Commonly used material models are: the Johnson-Cook (JC) material model (1983); the Maekawa model (1983); the Bammann-Chiesa-Johnson (BCJ) law (1996); the micromechanical model (Guo et al., 2006). The effects of strain hardening, thermal softening, dynamic strain aging, etc., are considered in these models. While some material models neglect the interaction between those effects (as in JC model), some have a lot of parameters to calculate (as in BCJ model). The levels of strain and strain rate observed 
at shear zones during machining are much higher than those attained by using Split-Hopkinson bar tests. As a result, the flow stress at high strains beyond the experimental range is calculated by extrapolation using constitutive models.

In this study, a modified material constitutive model based on the micromechanical material model developed by Anurag and Guo (2007) is proposed. In the modified model, the interrelationships between strain and temperature, strain and strain rate, and flow softening at high strains are added to this model. The developed material model exhibited a very good fit with experimental data, and it is employed in finite element simulations in order to investigate the influence of material model parameters on the simulation outputs. The outputs are compared with experimental results reported in Calamaz et al. (2008) and a good match is obtained in terms of cutting forces and chip morphology.

\section{MATERIAL CONSTITUTIVE MODEL}

In finite element models, an accurate material model is the key requirement for a successful process simulation. The material constitutive model should not only contain the necessary deformation parameters but also their interrelationships. For instance, the simplicity of Johnson and Cook (1983) model makes it a popular material constitutive model; however, it does not model the coupling effects of strain rate and temperature and strain and strain rate. These interactions play an important role in some materials, such as titanium alloy $T i-6 A l-4 \mathrm{~V}$.

Recently, Anurag and Guo (2007) proposed a micromechanical constitutive model to predict the material behavior of titanium alloy Ti-6Al-4 $\mathrm{V}$ based on the work of Nemat-Nasser and Isaacs (1997). In this model, the effect of strain rate and temperature on the flow stress is considered with a thermal stress term, and the effect of microstructure (i.e., dislocation density, average grain size) is represented with an athermal stress term. Anurag and Guo (2007) used the Split-Hopkinson bar test results reported in Lee and Lin (1998) and calculated the athermal part of the flow stress by considering the critical temperature at which flow stress becomes insensitive to temperature changes. This phenomena is called dynamic strain aging and they identified the critical temperature at which dynamic strain aging occurs from the stress vs. temperature plots obtained from Split-Hopkinson bar test results at a given strain rate. The athermal stress representation was obtained by a curve fitting approach from the strain vs. flow stress data at the identified critical temperature.

To predict flow stress above the critical temperature, they multiplied the athermal stress with a temperature coefficient and obtained a good fit 
TABLE 1 The Values of the Coefficients of the Material Model at $800 \mathrm{~s}^{-1}$ Strain Rate

\begin{tabular}{|c|c|c|c|c|c|}
\hline$(\mathrm{MPa})$ & $\mathrm{n}$ & $\mathrm{B}(\mathrm{MPa})$ & $\mathrm{C}$ & $\mathrm{D}$ & $\mathrm{E}$ \\
\hline 590 & 0.27 & 740 & $1.7976 \mathrm{e}-7$ & -0.001042 & 1.6356 \\
\hline
\end{tabular}

to experimental flow stress data. In this study, the material model proposed by Anurag and Guo (2007) is slightly modified so that an additional term is used in the power law relationship and a second-order polynomial is used for temperature function (Equation (1)). The unknown parameters $(A, B, C, D, E, n)$ can be calculated from the experimental data given in Lee and Lin (1998). The unknown parameters are calculated by using the procedure proposed in Anurag and Guo (2007) together with an optimization algorithm. The calculated parameters are shown in Table 1. Figure 1 shows the strain-stress curve obtained at various temperatures using the proposed model. A very good fit is obtained by using the proposed modified material model.

$$
\sigma(\varepsilon, \dot{\varepsilon}, T)=\left(A \varepsilon^{n}+B\right)\left(C T^{2}+D T+E\right)
$$

To add the influence of strain rate in Equation (1), the data given in Lee and Lin (1998) was investigated. Lee and Lin (1998) studied the interaction between strain and strain rate and calculated that $T i-6 A l-4 V$ 's strain rate sensitivity decreases with increasing strain. Strain rate sensitivity is defined as the difference in flow stress values at two different strain rate

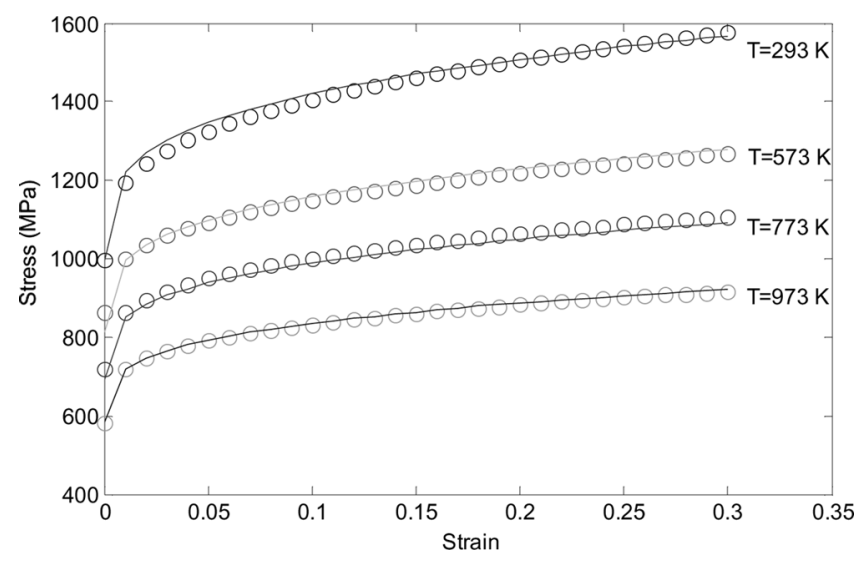

FIGURE 1 Flow stress at different temperatures at $800 \mathrm{~s}^{-1}$ strain rate based on data given in Lee and Lin (1998). 


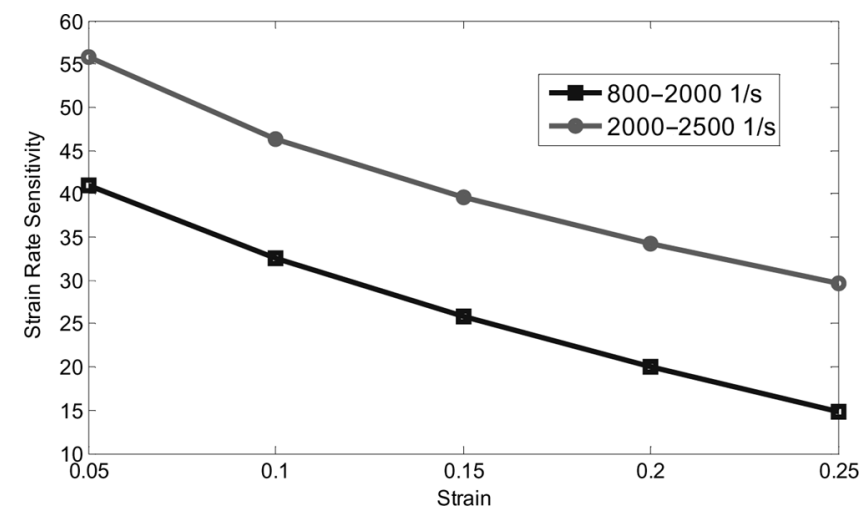

FIGURE 2 The relationship between strain rate sensitivity and strain (at $700^{\circ} \mathrm{C}$ ) (Lee and Lin, 1998).

levels at each strain, as in Equation (2).

$$
\beta=\frac{\left(\sigma_{2}-\sigma_{1}\right)}{\ln \left(\dot{\varepsilon}_{2} / \dot{\varepsilon}_{1}\right)}
$$

The results are shown in Figure 2. During deformation, the rate of thermal softening caused by increasing temperatures is greater than that of strain and strain rate hardening induced by plastic deformation, and thus it can be seen that strain rate sensitivity decreases rapidly with strain for all available strain rate ranges. The decreasing effect of strain rate on the flow stress with increasing strain is added to Equation (1) by using a tanh function, as shown in Equation (3). The reference strain rate $\left(\dot{\varepsilon}_{0}\right)$ is taken as $800\left(\mathrm{~s}^{-1}\right)$.

$$
\begin{aligned}
\sigma(\varepsilon, \dot{\varepsilon}, T) & =\left(A \varepsilon^{n}+B\right)\left(C T^{2}+D T+E\right) h(\varepsilon, \dot{\varepsilon}) \\
h(\varepsilon, \dot{\varepsilon}) & =1-\left[1-\left(\frac{\ln \left(\dot{\varepsilon}_{0}\right)}{\ln (\dot{\varepsilon})}\right)^{q}\right]\left[\frac{1}{L^{*} \tanh (\varepsilon+m)}\right]
\end{aligned}
$$

Figure 3(a) shows the decreasing effect of strain rate on the flow stress with increasing strain at various strain rates, including a very high strain rate typical in shear zones during machining. The unknown parameters of Equation (3), $L$ and $q$, are calculated as 1.1 and 0.035 by minimizing the difference between experimental data (Lee and Lin, 1998) and the material model. The parameter $m$ is taken as 0.08 in order to prevent tanh function to saturate at strains close to zero. This equation allows the calculation of flow stresses at high strain rates, and it can either be used directly or entered in a tabular form in finite element software. Figure 3(b) shows the influence of the strain rate expression of the proposed model on the flow stress curve as compared to the Johnson-Cook material model. 


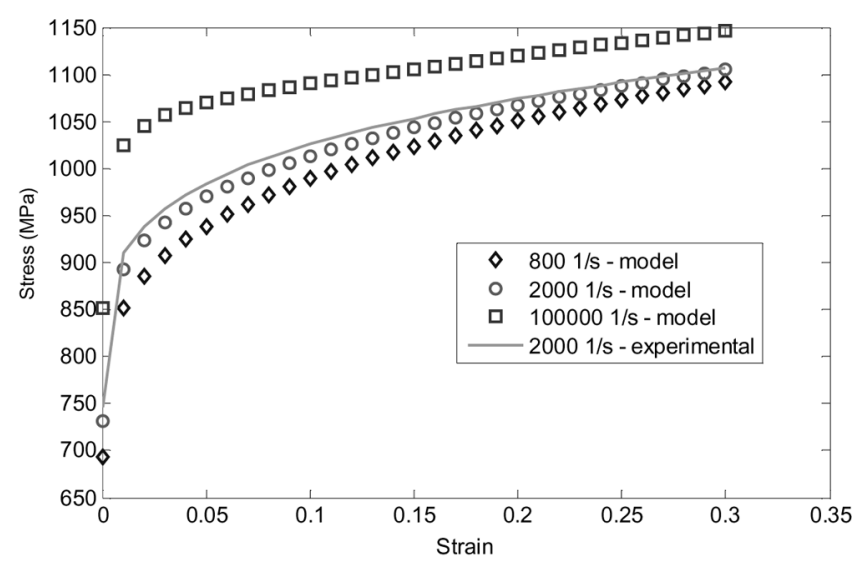

(a)

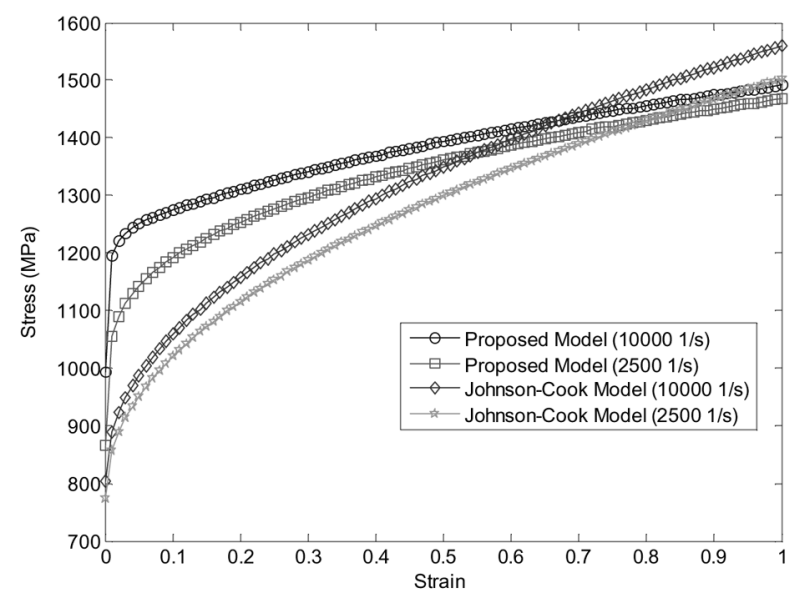

(b)

FIGURE 3 (a) The flow stress curve at low strains at $300^{\circ} \mathrm{C}$; (b) Comparison of the proposed model and the Johnson-Cook material model parameters calculated by Lee and Lin (1998) $(A=724$, $B=683.1, n=0.47, C=0.035, m=1)$.

Figure 4 summarizes the methodology of calculating the material model parameters of the proposed material model.

\section{Modeling Material Behavior at High Strains}

To include the effect of strain softening at high strains, an additional term is integrated into flow stress formulation similar to Calamaz et al. (2008), as shown in Equation (4). As discussed earlier, the underlying mechanism for the softening is not well understood. This mechanism can be related to ductile fracture at lower temperatures, where the softening is more pronounced. The critical strain is assumed to be constant for all 


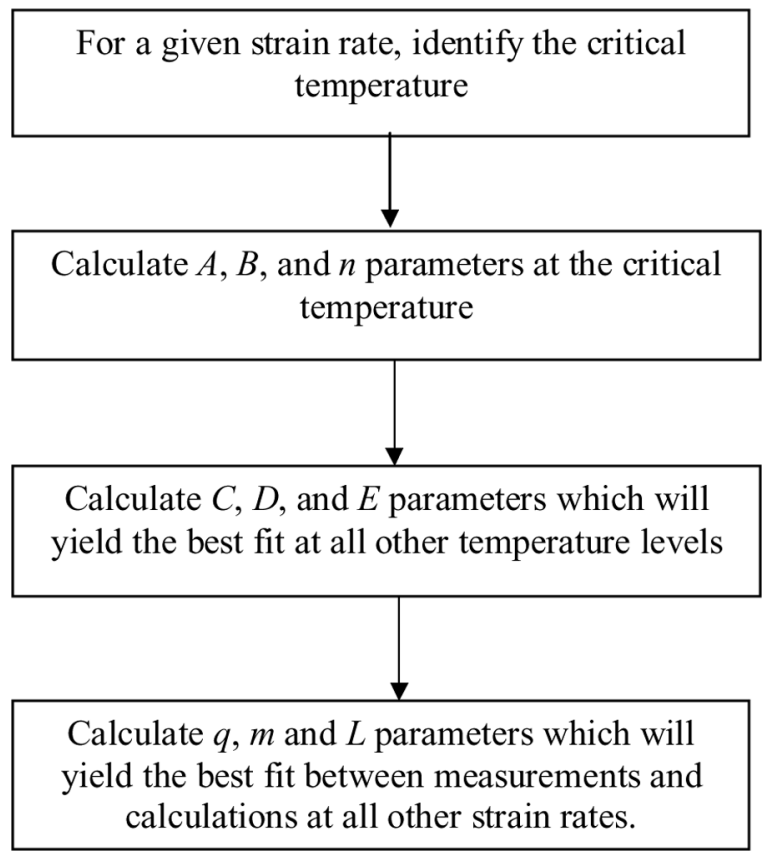

FIGURE 4 Methodology for calculating the material model parameters.

temperatures. The same softening rate is applied at all temperatures.

$$
\begin{array}{r}
\sigma(\varepsilon, \dot{\varepsilon}, T)=\left(A \varepsilon^{n}+B\right)\left(C T^{2}+D T+E\right) h(\varepsilon, \dot{\varepsilon}) g(\varepsilon) \\
g(\varepsilon)=\left[M+(1-M)\left[\tanh \left(\frac{1}{(\varepsilon+p)^{r}}\right)\right]^{s}\right]
\end{array}
$$

The softening part $(\mathrm{g}(\varepsilon))$ in Equation (4) includes another tanh function with the dual purpose of leaving flow stress values unchanged at low strains and introducing different levels of softening at higher strains through parameters $p, r, s$, and $M$. The parameter $M$ determines the strain where flow stress becomes constant and the parameter $s$ determines the rate of softening. The parameters $p$ and $r$ determine the critical strain where softening starts. In this study, $p$ is set at zero, and $r$ is set at one for simplicity and various combinations of $M$ and $s$ are considered in the finite element simulations.

\section{FINITE ELEMENT MODEL}

Finite element simulations of machining were performed using commercial software DEFORM 2D v9.1 (2008), which is based on updated Lagrangian formulation. The software allows the user to define flow stress 
TABLE 2 Summary of Flow Softening Parameters Used in Finite Element Simulations

\begin{tabular}{llr}
\hline Experiment \# & $M$ & $S$ \\
\hline 1 & 0.5 & 5 \\
2 & 0.5 & 15 \\
3 & 0.6 & 5 \\
4 & 0.65 & 5 \\
5 & 0.65 & 10 \\
6 & 0.7 & 7 \\
7 & 1 & 0 \\
\hline
\end{tabular}

model as a function of strain, strain rate, and temperature. Cutting tool material is uncoated carbide and modeled as rigid in the simulations. In the finite element model, the workpiece is modeled as elasto-plastic. The workpiece is represented with 10,000 quadrilateral elements (maximum number in DEFORM) whereas 3,500 quadrilateral elements are used to represent the cutting tool. A mesh window is used around the edge radius of the cutting tool for better representation of that area.

In this study, a "design of computer experiments" approach is used to understand the influence of flow softening parameters, which are listed in Table 2, on the simulation outputs. Figure 5 represents the softening at high strains for different values of the parameters $s$ and $M$.

As mentioned earlier, orthogonal cutting data given in Calamaz et al. (2008) is used in this study. In the experiments, uncut chip thickness is taken as $0.1 \mathrm{~mm}$ and 2 different cutting speeds $(60$ and $180 \mathrm{~m} / \mathrm{min}$ ) are considered. A cutting tool with an edge radius of $20 \mu \mathrm{m}$ and negative $15^{\circ}$ rake angle was used. Proper boundary conditions are applied as the cutting tool is modeled as fixed and the workpiece is considered as moving at above-mentioned cutting speeds.

Friction at the tool chip and tool workpiece interfaces directly affects the heat generation, thereby influencing the process outputs, such as cutting forces, stresses, temperatures, etc. In finite element models, the Coulomb friction model, and/or the shear friction model are commonly used. Ozel (2006) compared the effect of four different friction models on simulation outputs and concluded that the variable friction coefficient yields the best results.

Karpat and Özel (2008) defined the friction on the cutting tool by using friction windows when machining with negative rake angle cutting tools with edge radius and obtained good results with this friction definition. Similarly, sticking conditions (friction factor $=1$ ) are considered around the edge radius by using a friction window, and rake face friction is defined with an average shear friction factor, as shown in 


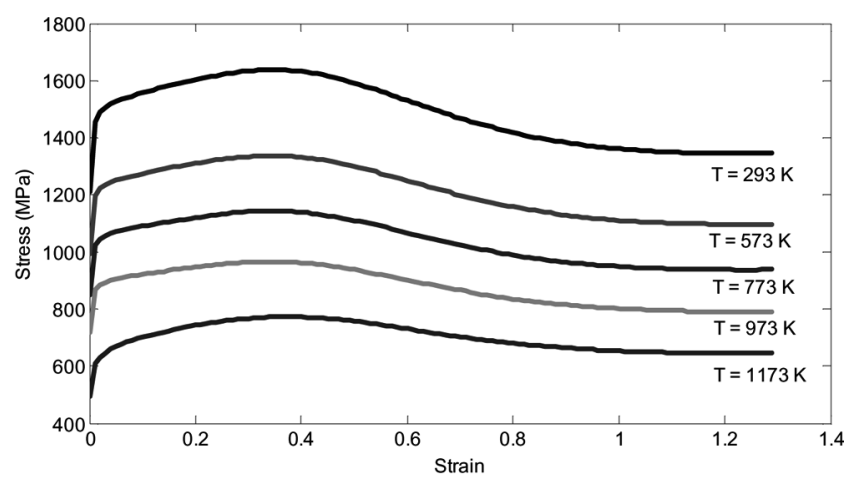

(a)

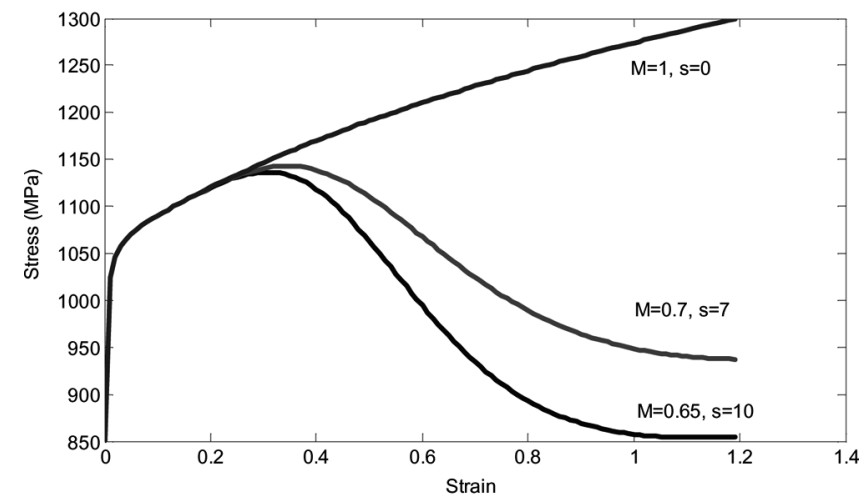

(b)

FIGURE 5 (a) The effect of softening parameter at all temperature levels, (b) The effect of various softening parameters on the flow stress at higher strains at $T=300^{\circ} \mathrm{C}$.

Figure 6. In finite element simulations, the rake face friction factor is taken as 0.7 for the cutting speed of $180 \mathrm{~m} / \mathrm{min}$ and 0.75 for the cutting speed of $60 \mathrm{~m} / \mathrm{min}$ since a previous study had found analytically that shear factor decreases with increasing cutting speed (Karpat and Özel, 2008).

To simulate the movement of the cutting tool in the workpiece, a chip separation criterion must be defined. Chip separation can be achieved by remeshing the distorted elements around the cutting edge. The overlap distance between the cutting tool and the workpiece at the tool workpiece interface is used as a trigger for remeshing. As a result of remeshing, the mesh data are mapped from old mesh to new mesh. Figure 7 summarizes the input parameters in a finite element simulation. The cutting tool geometry and workpiece dimensions are set at the beginning of the simulation. Remeshing and chip separation are controlled by the software during the simulation. 


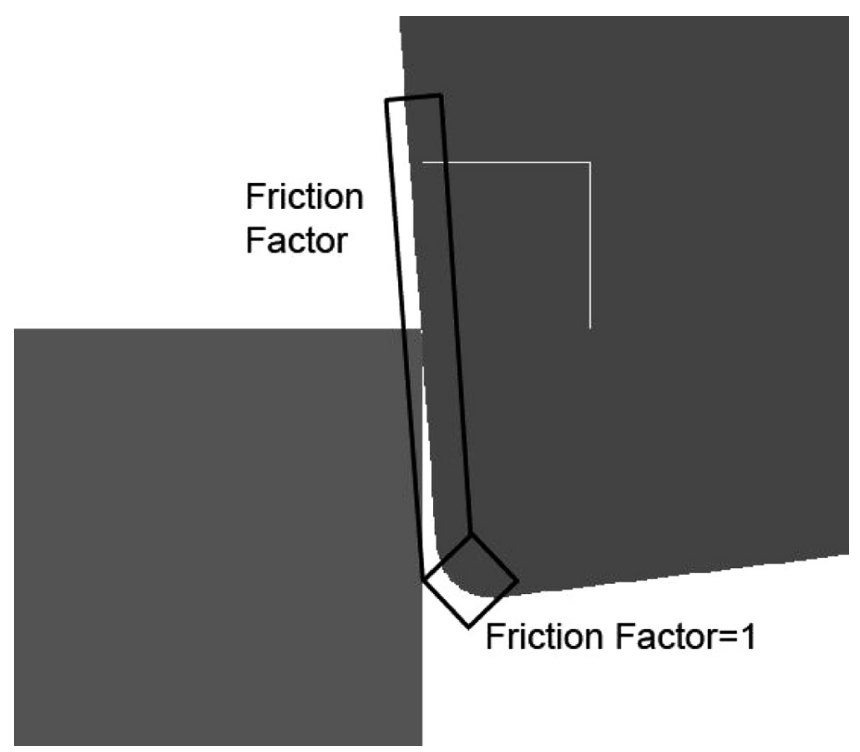

FIGURE 6 Friction definition used in the simulations.

\section{Elastic and Thermal Properties of Titanium Alloy Ti-6AI-4V}

The elastic (Young's modulus, Poisson ratio, thermal expansion) and thermal (heat capacity, thermal conductivity) properties of the titanium Ti-6Al-4V alloy (Richter, 1988; Müller, 2004; Messner, 2006) are briefly described next.

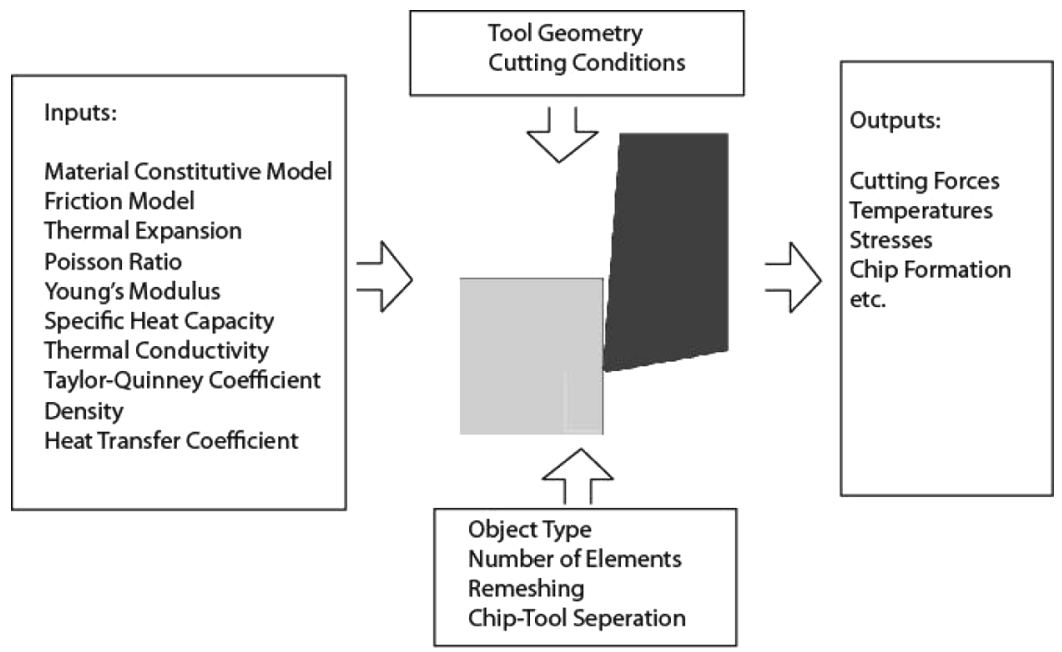

FIGURE 7 A summary of inputs and outputs to finite element simulation. 


\section{Young's Modulus (E)}

The Young's modulus is an elastic material property and represents the linear relationship between stress and strain in the elastic deformation zone. It strongly depends on temperature and decreases with increasing temperature. The relationship between the temperature and Young's modulus can be expressed with Equation (5) using linear extrapolation. In order to prevent Young's modulus being zero, its value may be limited to a constant value at high temperatures.

$$
E(T)=-57.7^{*} T+111672(\mathrm{MPa})
$$

\section{Poisson Ratio}

The elongation of the workpiece under tensile loading is accompanied by lateral contraction. The absolute value of elongation to contraction is known as the Poisson ratio. In this study, the Poisson ratio of $T i-6 \mathrm{Al}-4 \mathrm{~V}$ is taken constant as 0.26 .

\section{Thermal Expansion Coefficient $(\alpha)$}

The thermal expansion coefficient describes the change in volume caused by a variation of the temperature. The coefficient of thermal expansion shows a dependency on the temperature so that it increases with increasing temperature. The linear relationship between thermal expansion coefficient and temperature can be obtained as Equation (6).

$$
2 e-9^{*} T+9 e-6
$$

\section{Heat Capacity $\left(c_{p}\right)$}

The heat capacity measures the change in internal energy per degree of temperature change per unit volume. The heat capacity is the product of specific heat capacity and density of the material. The heat capacity depends on the temperature and is influenced by phase transformation of the material. It is defined with Equation (7).

$$
C_{p}(T)=2.7 e 0.0002^{*} T\left(\mathrm{~N} / \mathrm{mm}^{2} /{ }^{\circ} \mathrm{C}\right)
$$

\section{Thermal Conductivity $(\lambda)$}

Thermal conductivity is defined as the ability of the material to conduct heat. It can be represented as a function of temperature, as in 
Equation (8),

$$
\lambda(T)=0.015^{*} T+7.7(\mathrm{~W} / \mathrm{m} \cdot \mathrm{K})
$$

In addition to these, other input parameters, such as heat transfer coefficient, Taylor-Quinney coefficient, and heat convection coefficient also affect temperature distribution at the cutting zone. However, it is difficult to reliably determine these input parameters. The heat transfer coefficient can be defined as constant or as a function of the pressure distribution at the chip tool interface.

The roughness of contacting surfaces affects the heat transfer coefficient. Heat transfer coefficient at the tool-chip interface is taken as constant at $10,000 \mathrm{~W} / \mathrm{m}^{2 \circ} \mathrm{C}$. This coefficient mainly affects the temperature distributions in the cutting tool. The Taylor-Quinney coefficient determines mechanical to heat energy conversion percentage and is typically taken as 0.9 in machining simulations. The heat convection coefficient is also required to determine heat transfer from the cutting zone to the environment and is taken as $0.02 \mathrm{~N} / \mathrm{sec} / \mathrm{mm} /{ }^{\circ} \mathrm{C}$.

\section{SIMULATION RESULTS}

Titanium alloy $T i-6 A l-4 V$ produces serrated chips, even at very low cutting speeds. In serrated chips, low and high deformation zones are separated by thin shear bands. Due to high strains in machining, the deformation results in adiabatic temperature rise, which is concentrated in a shear band in a very short time. In order to investigate the effect of softening parameters (Table 2) on the process outputs, simulations at different parameter settings were run. Figure 8 shows the simulated chips at cutting speed $180 \mathrm{~m} / \mathrm{min}$ with different softening parameters. The shear bands are visible in the effective strain plots, as shown in Figures $8(\mathrm{a}-\mathrm{f})$. A continuous chip is obtained when the softening is not considered, as shown in Figure $8(\mathrm{~g})$. As the parameter $s$ increases and the parameter $M$ decreases, chip serration increases and the radius of curvature of the chips decreases.

To observe the effect of softening parameters, experimentally measured and simulated cutting forces are compared. Figure 9(a) shows the effect of softening parameters on the simulated mean cutting forces. Softening parameters $M=0.7$ and $s=7$ yielded the closest results in terms of cutting forces.

Figure 9(b) shows the comparison of experimental and simulated cutting forces. In terms of cutting forces, the largest error in all simulations is $8 \%$. It must be noted that friction factor is kept constant in this study. A better match could be obtained by changing rake face friction factor. 


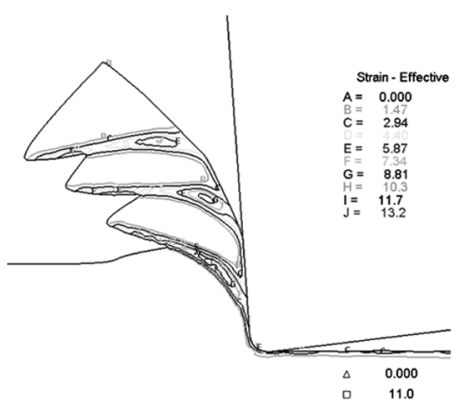

(a) $M=0.5, s=5$

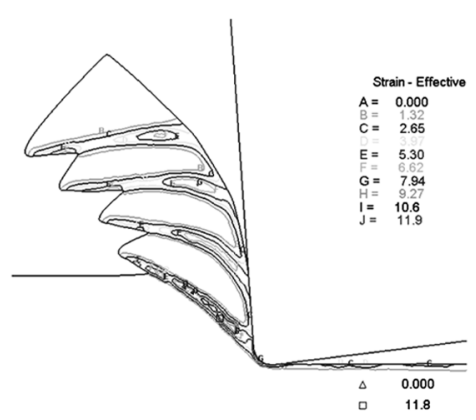

(c) $M=0.6, s=5$

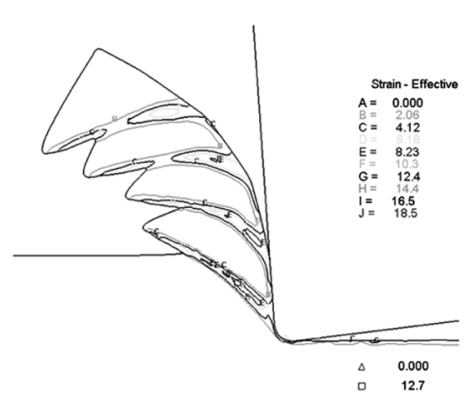

(e) $M=0.65, s=10$

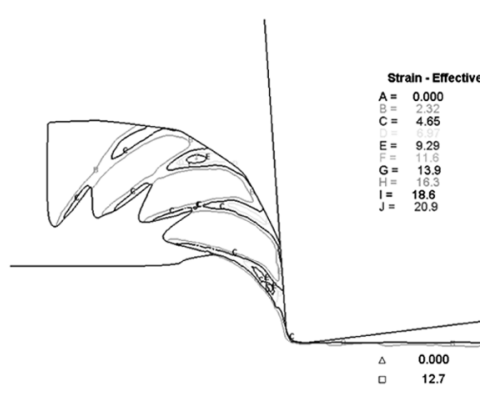

(b) $M=0.5, s=15$

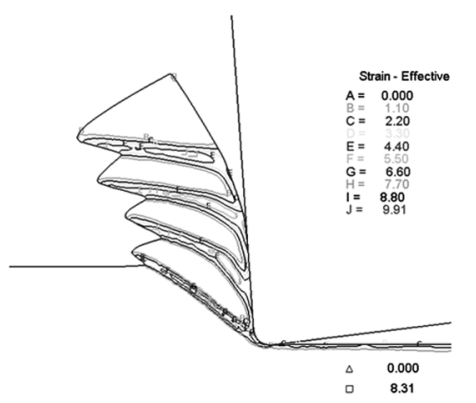

(d) $M=0.65, s=5$

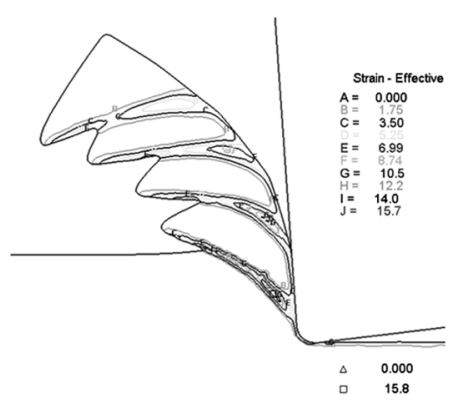

(f) $M=0.7, s=7$

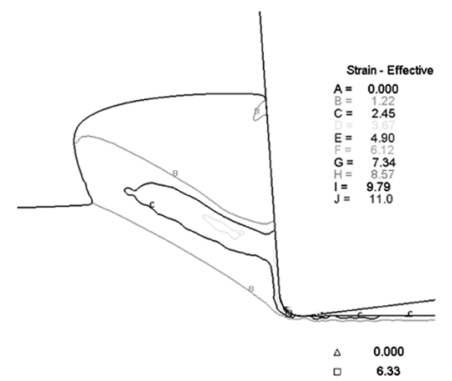

(g) $M=1, s=0$

FIGURE 8 The effect of softening parameters on the simulated chips at $V=180 \mathrm{~m} / \mathrm{min}$. 


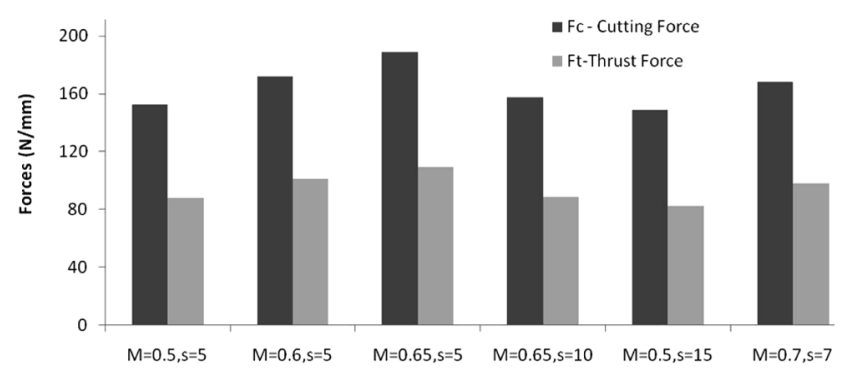

(a)

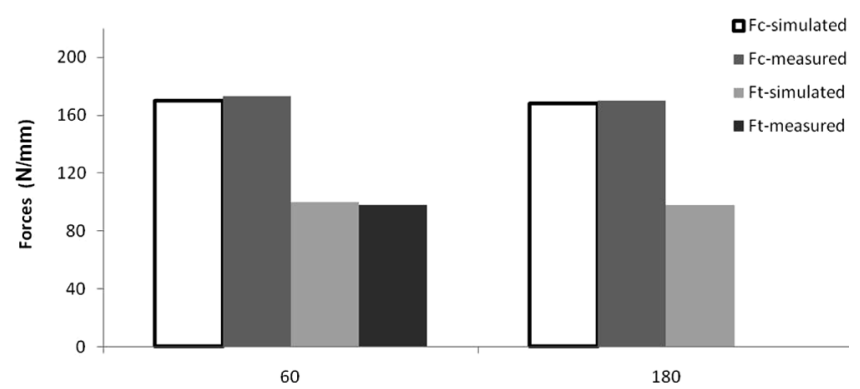

(b)

FIGURE 9 (a) Comparison of simulated cutting forces with respect to softening parameters at $V=180 \mathrm{~m} / \mathrm{min}$; (b) Comparison of experimental and simulated cutting forces at two different cutting speeds $(60 \mathrm{~m} / \mathrm{min}$ and $180 \mathrm{~m} / \mathrm{min})$ with $M=0.7$ and $s=7$.

Figures $10(\mathrm{a})$ and $10(\mathrm{~b})$ show the simulated cutting forces for $V=60 \mathrm{~m} / \mathrm{min}$ and $V=180 \mathrm{~m} / \mathrm{min}$. Cutting forces fluctuate due to chip serration. The chip formation frequency can be calculated as $11 \mathrm{kHz}$ for $V=60 \mathrm{~m} / \mathrm{min}$ and $29 \mathrm{kHz}$ for $V=180 \mathrm{~m} / \mathrm{min}$ from these diagrams. The experimental values were given as 10 and $30 \mathrm{kHz}$ in Calamaz et al. (2008). Therefore a good match in terms of chip formation frequency is obtained. It must be noted that chip formation frequency is directly proportional to cutting speed.

Figures 11(a) and 11(b) show the simulated chips at cutting speeds $60 \mathrm{~m} / \mathrm{min}$ and $180 \mathrm{~m} / \mathrm{min}$. The measured maximum chip thickness is $131 \mu \mathrm{m}$, minimum chip thickness is $62 \mu \mathrm{m}$, and the tooth width is $100 \mu \mathrm{m}$ (Calamaz et al., 2008). The simulated maximum chip thickness is $138 \mu \mathrm{m}$, minimum chip thickness is $81 \mu \mathrm{m}$, and the tooth width is $63 \mu \mathrm{m}$. From these results, although the maximum simulated chip thickness agrees well with the experiment, minimum chip thickness and tooth width values are over predicted in the simulations.

Figure 12 shows the velocity and temperature fields during the formation of a tooth. According to finite element simulations, material buildup at the beginning of the tooth formation and a temperature rise in front of the cutting tool edge radius can be seen in Figure 12(a). At this point, material sticks to the rake face of the cutting tool, the 


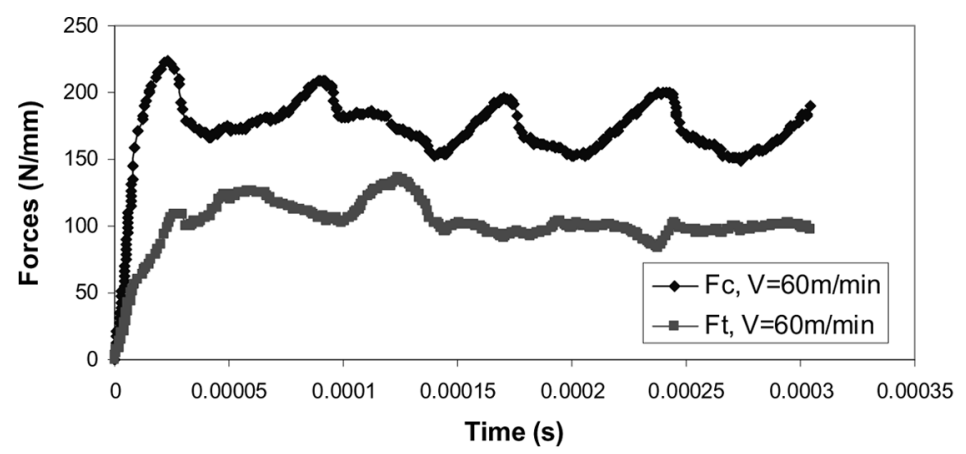

(a)

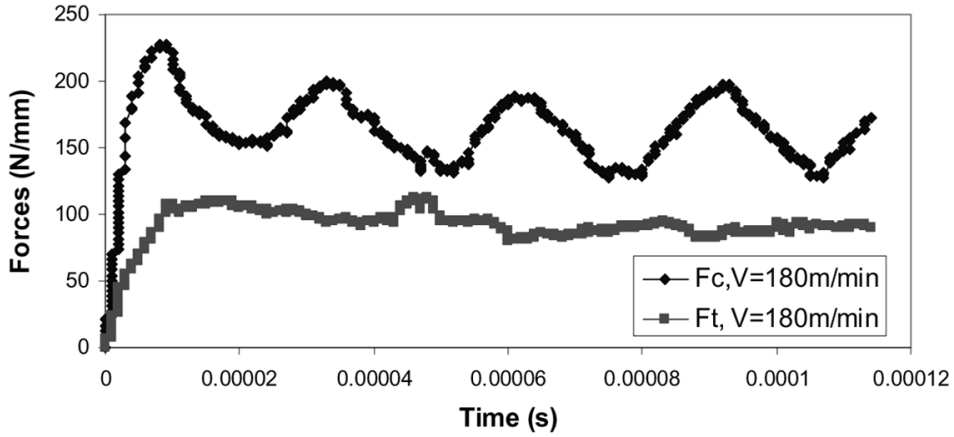

(b)

FIGURE 10 (a) Simulated cutting forces vs. time for $V=60 \mathrm{~m} / \mathrm{min}$, (b) $V=180 \mathrm{~m} / \mathrm{min}$ with $M=0.7$ and $s=7$.

temperatures on the primary shear zone start to increase, and adiabatic shear zone initiates in front of the tool. Once the average temperatures on the primary shear zone approach $400^{\circ} \mathrm{C}$, material accumulation stops and tooth formation initiates and propagates until the maximum temperature

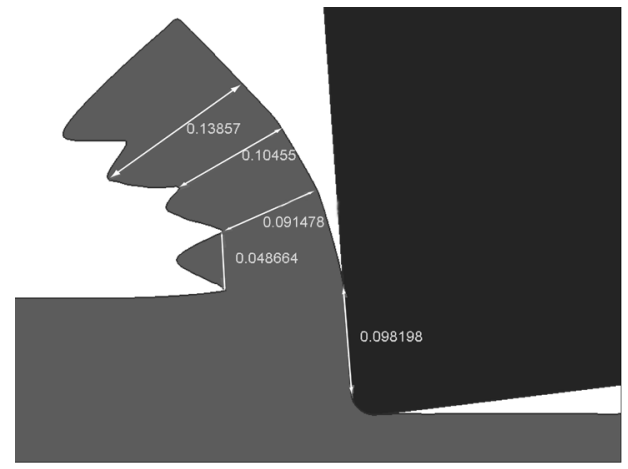

(a)

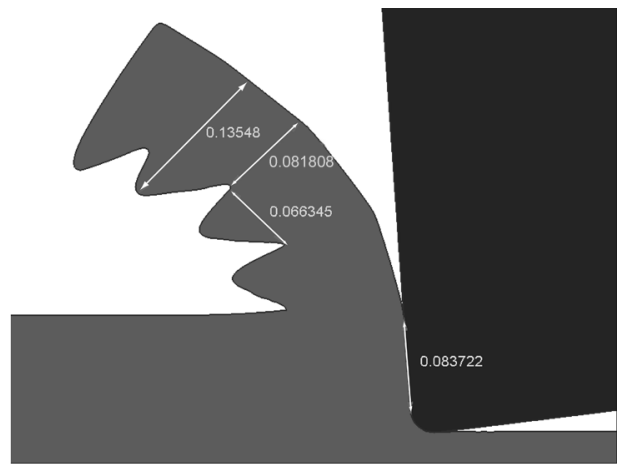

(b)

FIGURE 11 Simulated chips (a) $V=60 \mathrm{~m} / \mathrm{min}$, (b) $V=180 \mathrm{~m} / \mathrm{min}$. 

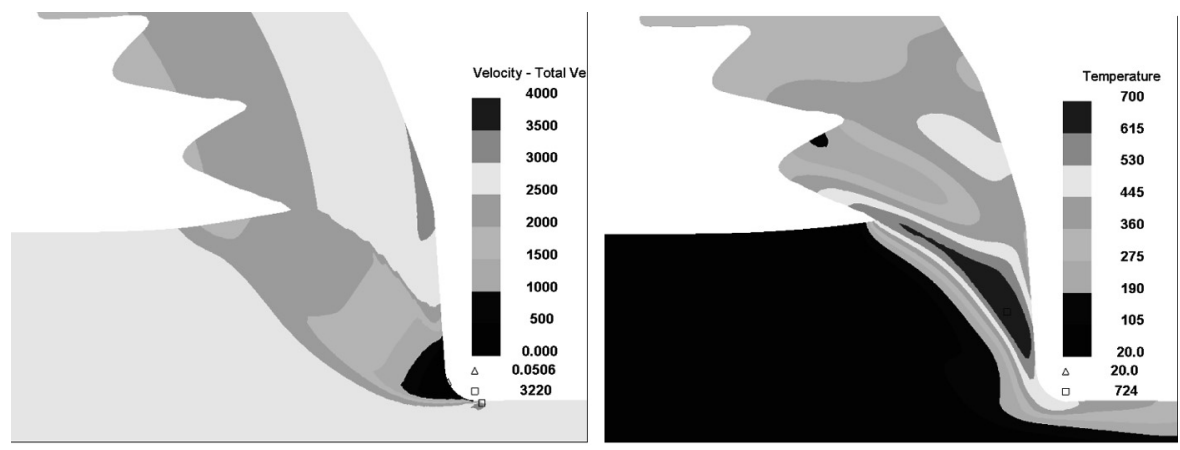

(a)

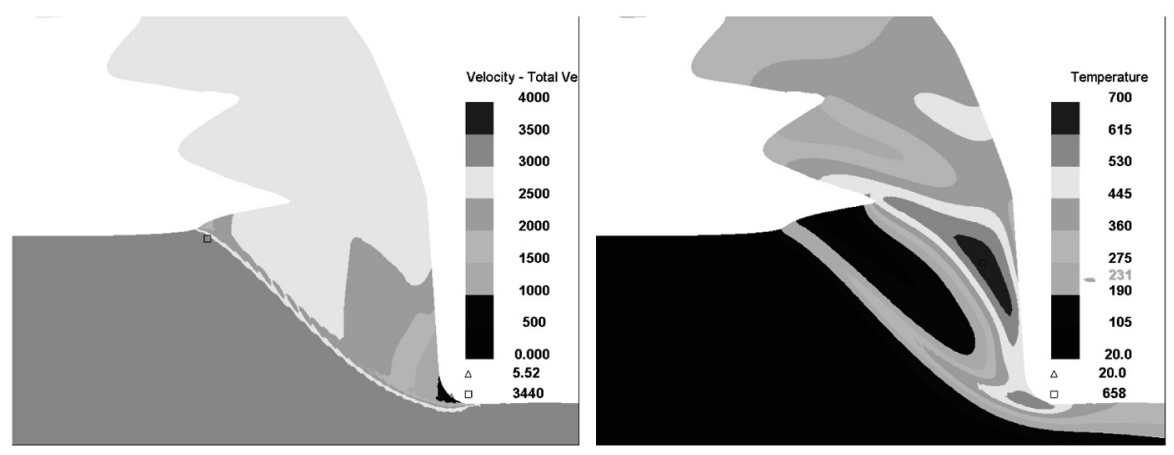

(b)

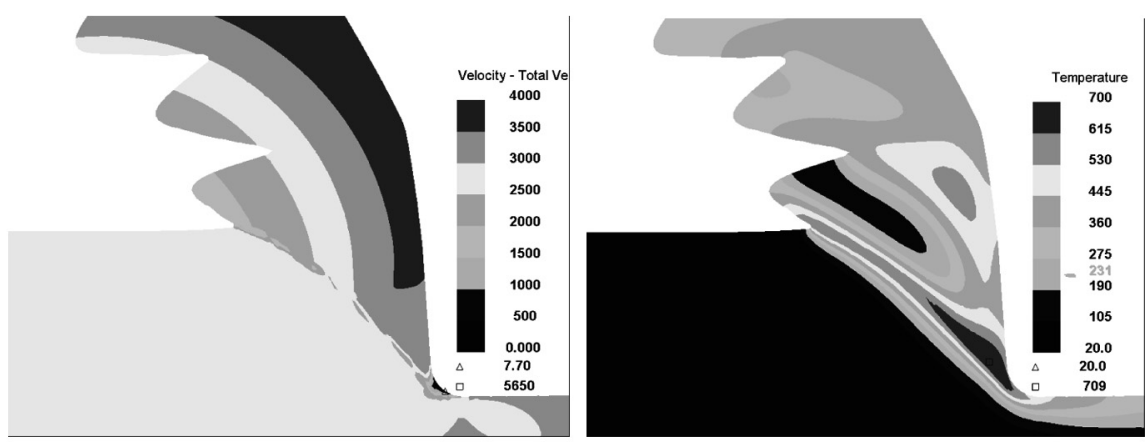

(c)

FIGURE 12 Velocity and temperature distributions during (a) initial, (b) intermediary, (c) final phase of the chip formation for cutting speed $V=180 \mathrm{~m} / \mathrm{min}$.

in the shear band reaches around $700^{\circ} \mathrm{C}$ (Figure $\left.12(\mathrm{~b})\right)$. After this, the sticking contact zone on the rake face decreases and the contact between the tool and the chip becomes mainly sliding until the next tooth forms (Figure 12(c)). 


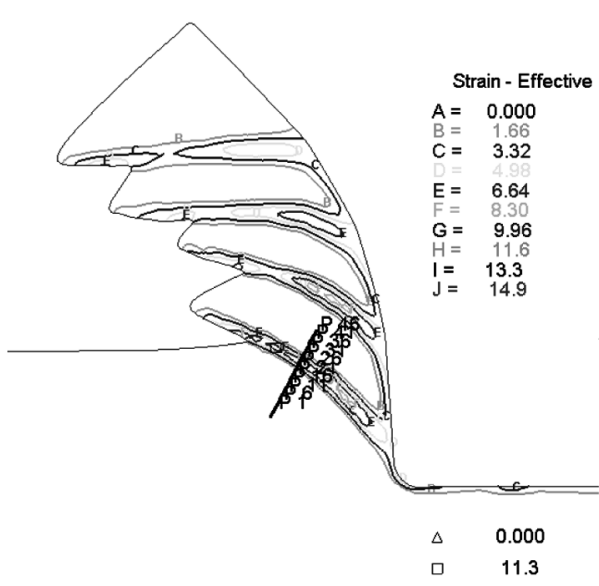

(a)

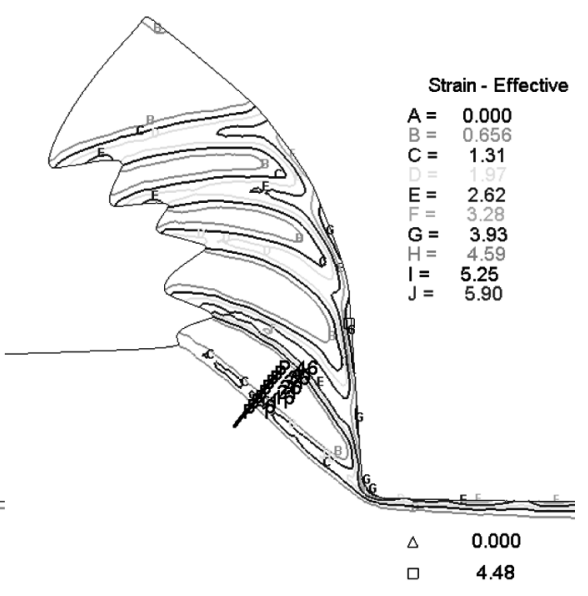

(b)

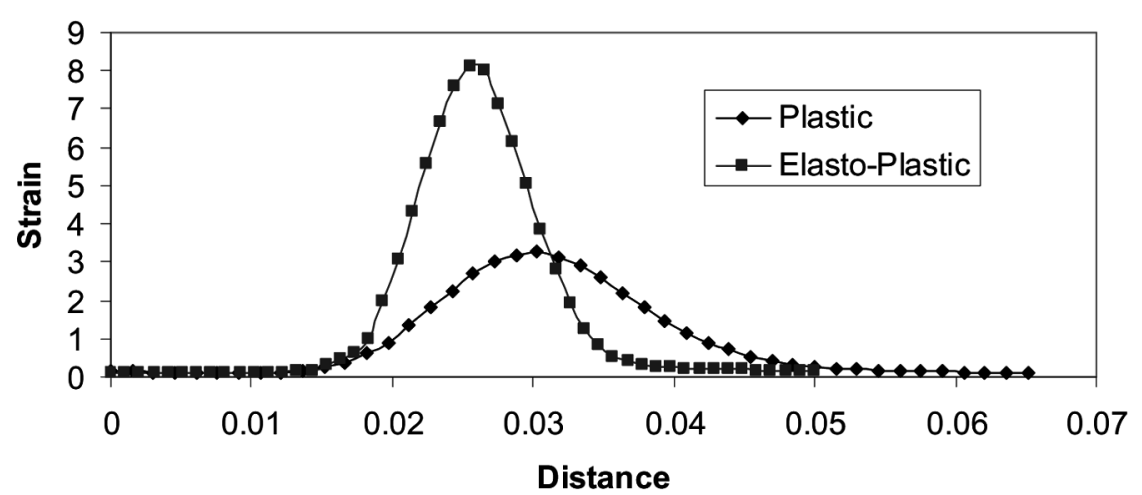

(c)

FIGURE 13 Strain distribution in (a) elasto-plastic model, (b) plastic model, (c) across the shear band for plastic and elasto-plastic models for the cutting speed $V=60 \mathrm{~m} / \mathrm{min}$.

The influence of finite element formulation is also investigated by running a plastic finite element simulation model. The differences between plastic and elasto-plastic simulations were compared, as shown in Figure 13(a). The effective strain distribution at a location in the middle of the shear band is found to be higher in the elasto-plastic simulation model. The shear band is narrower, and the chip serration is larger. Figure 13(b) shows the strain distribution across the shear bands.

Figure 14 represents the variation of shear angle during machining. The change in shear angle changes the average strains in the primary shear zone and affects heat generation in that area. The average shear angle can be calculated as $39^{\circ}$, which is in good accordance with the experimental results. The sharp drop in the shear angle corresponds to the formation of adiabatic shear bands initiating from in front of the cutting tool. 


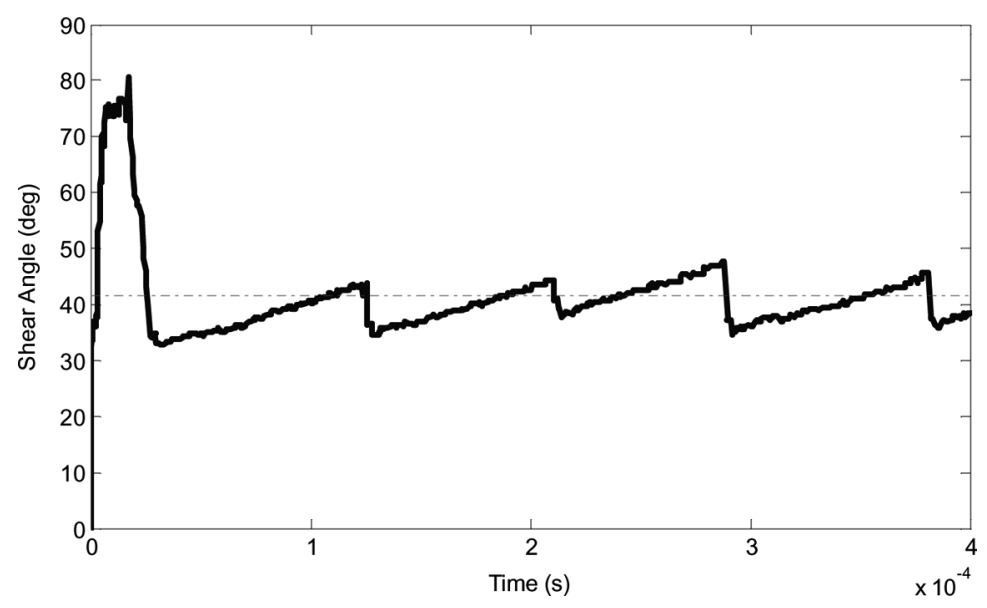

FIGURE 14 Shear angle variation vs. time at cutting speed $V=60 \mathrm{~m} / \mathrm{min}$.

\section{CONCLUSIONS}

In this study, a modified material constitutive model that considers the interrelationships between the strain-strain rate and temperature-strain is proposed for the machining of titanium alloy $T i-6 A l-4 \mathrm{~V}$. The flow softening effect at high strains is also included in the model and the influences of various softening parameters on the simulation outputs have been investigated. Finite element simulation results reveal that the proposed material model produces realistic process outputs in agreement with experimental observations, especially in terms of cutting forces. It can therefore be concluded that:

(a) Finite element simulations may yield realistic results if the material model and other simulation inputs are well set.

(b) Elasto-plastic model simulations yield more reasonable results than the plastic model at a cost of longer simulation time.

(c) It is possible to simulate serrated chip formation without employing a damage model.

\section{ACKNOWLEDGMENT}

The author would like to acknowledge the financial support from The Scientific and Technological Research Council of Turkey-TUBITAK.

\section{REFERENCES}

Anurag, S.; Guo, Y.B. (2007) A modified micromechanical approach to determine flow stress of work materials experiencing complex deformation histories in manufacturing processes. International Journal of Mechanical Sciences, 49(7):909-918. 
Aurich, J.C.; Bil, H. (2006) 3D Finite element modeling of segmented chip formation. CIRP AnnalsManufacturing Technology, 55(1):47-50.

Bäker, M.; Rosler, J.; Siemers, C. (2002) A finite element model of high speed metal cutting with adiabatic shearing. Computers $\mathcal{E}$ Structures, 80(5-6):495-513.

Bammann, D.J.; Chiesa, M.L.; Johnson, G.C. (1996) Modeling large deformation and failure in manufacturing processes. In: Theoretical and Applied Mechanics, ed. T. Tatsumi, E. Wannabe, and T. Kambe, Elsevier Science, Amsterdam, 359-376.

Barry, J.; Byrne, G.; Lennon, D. (2001) Observations on chip formation and acoustic emission in machining Ti-6Al-4V alloy. International Journal of Machine Tools E Manufacture, $41(7): 1055-1070$.

Burns, T.J.; Davies, M.A. (2002) On repeated adiabatic shear band formation during high speed machining. International Journal of Plasticity, 18(4):487-506.

Calamaz, M.; Coupard, D.; Girot, F. (2008) A new material model for 2D numerical simulation of serrated chip formation when machining titanium alloy Ti-6Al-4 V. International Journal of Machine Tools $\mathcal{E}$ Manufacture, 48(3-4):275-288.

Deform 2D Version 9.1, 2008, Scientific Forming Technologies Corporation, Columbus, Ohio, USA.

Giovanola, H. (1988) Adiabatic shear banding under pure shear loading, part II: Fractographic and metallographic observations. Mechanics of Materials, 7(1):73-87.

Guo, Y.B.; Wen, Q.; Woodbury, K.A. (2006) Dynamic material behavior modeling using internal state variable plasticity and its application in hard machining simulations. Journal of Manufacturing Science and Engineering, 128(3):749-756.

Johnson, G.R.; Cook, W.H. (1983) A constitutive model for metals subjected to large strains, high strain rates and high temperatures. In: Proceedings of the Seventh International Symposium, Ballis, Hague, Netherlands, 54:1-7.

Karpat, Y.; Özel, T. (2008) Mechanics of high speed cutting with curvilinear edge tools. International Journal of Machine Tools E Manufacture, 48(2):195-208.

Komanduri, R.; Turkovich, B.F. (1981) New observations on the mechanism of chip formation when machining titanium alloys. Wear, 69(2):179-188.

Komanduri, R.; Brown, R.H. (1981) On the mechanics of chip segmentation in machining. Transactions of Mechanical Engineers Journal of Engineering for Industry, 103(1):33-51.

Lee, W.; Lin, C. (1998) High-temperature deformation behavior of Ti6Al4V alloy evaluated by high strain-rate compression tests. Journal of Materials Processing Technology, 75(1-3):127-136.

Maekawa, K; Shirakashi, T; Usui, E. (1983) Flow stress of low carbon steel at high temperature and strain rate (Part 2). Bulletin of the Japan Society of Precision Engineering, 17(3):167-172.

Medyanik, S.N.; Liu, W.K.; Li, S. (2007) On criteria for dynamic adiabatic shear band propagation. Journal of the Mechanics and Physics of Solids, 55(7):1439-1461.

Messner, G.F.L (2006) Modelling Metal Cutting Processes under Consideration of Elastic Material Properties, Ph.D. Dissertation, RWTH Aachen.

Miller, R.M.; Bieler, T.R.; Semiatin S.L. (1999) Flow softening during hot working of Ti-6al-4v with a lamellar colony microstructure. Scripta Materialia, 40(12):1387-1393.

Müller, B. (2004) Thermische Analyse des Zerspanensmetallischer Werkstoffe bei hohen, Schnittgeschwindigkeiten, RWTH Aachen.

Nemat-Nasser, S.; Isaacs, J.B. (1997) Direct measurement of isothermal flow stress of metals at elevated temperatures and high strain rates with application to Ta and Ta-W alloys. Acta Materialia, 45(3):907-919.

Recht, R.F. (1964) Catastrophic thermoplastic shear. Transactions of American Society of Mechanical Engineers, 86:189-193.

Rhim, S.H.; Oh, S.I. (2006) Prediction of serrated chip formation in metal cutting process with new flow stress model for AISI 1045 steel. Journal of Materials Processing Technology, 171(3):417-422.

Richter, F. (1988) Die physikalischen Eigenschaften der beiden Titan-Werkstoffe Ti 99,7 (3.7035) und TiAl6V4 (3.7165). Metall., 42(6):572-575.

Rittel, D.; Landau, P.; Venkert, A. (2008) Dynamic recrystallization as a potential cause for adiabatic shear failure. Physical Review Letters, 101, 165501.

Shivpuri, R.; Hua, J.; Mittal, P.; Srivastava A.K. (2001) Microstructure-mechanics interactions in modeling chip segmentation during titanium machining. CIRP Annals-Manufacturing Technology, 51(1):85-89. 
Timothy, S.P., Hutchings, J.M. (1984) Proc. 3rd Int. Conf. on Mechanical Properties at High Rates of Strain, J. Harding, ed., Institute of Physics, Bristol, 70:397-404.

Obikawa, T.; Usui, E. (1996) Computational machining of titanium alloy-finite element modelling and a few results. Journal of Manufacturing Science Engineering, Transactions of the ASME, 118:208-215.

Owen, D.R.J.; Vaz, M. (1999) Computational techniques applied to high-speed machining under adiabatic strain localization conditions. Computer Methods in Applied Mechanics and Engineering, $171(3-4): 445-461$.

Ozel, T. (2006) The influence of friction models on finite element simulations of machining. International Journal of Machine Tools and Manufacture, 46(5):518-530.

Umbrello, D. (2008) Finite element simulation of conventional and high speed machining of Ti6Al4V alloy. Journal of Materials Processing Technology, 196(1-3):79-87.

Xu, Y.; Zhang, J.; Bai, Y.; Meyers, M.A. (2008) Shear localization in dynamic deformation: microstructural evolution. Metallurgical and Materials Transactions, 39A:811-843. 